\title{
Oesophageal motor function before and after healing of oesophagitis
}

\author{
P Singh, A Adamopoulos, R H Taylor, D G Colin-Jones
}

\begin{abstract}
Forty three patients with reflux oesophagitis were studied to investigate the effect of healing on oesophageal function. All patients underwent oesophageal manometry and transit studies before and after complete healing of oesophagitis. Oesophagitis was treated with omeprazole $40 \mathrm{mg} /$ day for a median duration of 12 weeks. Twenty three patients also had an acid clearance test before and after healing. Thirty eight of the 43 patients had 24 hour oesophageal pH monitoring before treatment and this was repeated after healing (while on omeprazole) in 31 of them. Thirty four volunteers served as controls. All volunteers underwent manometry, 33 had oesophageal transit studies, and 23 had acid clearance test. Patients had significantly reduced lower oesophageal sphincter pressures and distal and middle oesophageal amplitudes, longer durations of contraction, and slower velocity of propagation than the controls $(16.5 v 22.5$ $\mathrm{mm} \mathrm{Hg} ; 52 v 92 \mathrm{~mm} \mathrm{Hg} ; 46 v 79 \mathrm{~mm} \mathrm{Hg} ; 3.1 v$ 2.7 seconds; and $3.3 v 4.1 \mathrm{~cm} /$ second respectively with the corresponding $p$ values $=0.017$ $0.0001 ; 0.0001 ; 0.017$; and 0.006 ). Patients had significantly longer transit times $(9 v 7$ and $17 v$ 11 seconds: $p=0.027$ and 0.002 for erect and supine postures respectively). They also had longer acid clearance times ( $350 v 288$ and 536 $v 405$ seconds: $\mathrm{p}=\mathbf{0 . 0 4 4}$ and $\mathbf{0 . 0 1 6}$ for sitting and supine postures respectively). There was no significant change in any of the indices of oesophageal function after healing of oesophagitis (lower oesophageal sphincter pressure $=16.5 v 20$; distal amplitude $=52 v 60$; middle amplitude $=46 v 49$; duration of contraction $=3.1 v 3.1$; velocity $=3.3 v 3.3$; erect transit time $=9 v 9$; supine transit time $=17 v 24$; acid clearance test (sitting) $=350 v$ 371; acid clearance test (supine) $=536 v 645$ ). These results incidate that oesophageal motor dysfunction in reflux oesophagitis is a primary phenomenon. (Gut 1992; 33: 1590-1596)
\end{abstract}

The key element in the pathogenesis of reflux oesophagitis is the acid load at the oesophageal mucosal surface which is a function of the hydrogen ion concentration and the duration of exposure to it. The degree of acid load is in turn determined by the barrier function of the lower oesophageal sphincter and the ability of the oesophagus to expel any refluxate back into the stomach. The latter is dependent on the effectiveness of peristaltic function.

Several studies have shown the association of reflux oesophagitis with lower oesophageal sphincter dysfunction and impaired oesophageal peristalsis. ${ }^{13}$ Oesophageal transit measured by scintigraphic techniques has similarly been shown to be slower in this condition. ${ }^{4}$ Patients with reflux oesophagitis also take longer to clear acid instilled into the oesophagus." "While there is no dispute that these abnormalities are commonly present in patients with reflux oesophagitis, there is a continuing debate as to whether these are primary phenomena or the consequences of repetitive injury and inflammation caused by acid reflux.

Previous studies on this subject have reported conflicting results. ${ }^{27 \times 11+4}$ Moreover, all of these studies either involved very small numbers 271214 or had other serious methodological flaws such as lack of objective criteria over initial recruitment or the response to treatment, or both, ${ }^{\times 1111}$ and lack of a control group. ${ }^{7214}$

Because of the uncertainty surrounding this important issue we undertook this study, looking at a much larger number of patients and measuring several indices of oesophageal function.

\section{Subjects and methods}

\section{PATIENTS}

Forty three patients ( 31 men) with a median age of 52 years (range 23-77) who had endoscopically documented oesophagitis were studied. Patients aged $>80$ years and those with oesophageal stricture, history of upper gastrointestinal surgery, or other serious coexistent medical conditions were excluded. The severity of oesophagitis was graded endoscopically accord-

TABLE I Demographic details of study subjects

\begin{tabular}{lll}
\hline & Controls & Patients \\
\hline Age (years) (median (range)) & $33 \cdot 5(22-51)$ & $52(23-77)$ \\
Sex (M:F) & $22: 12$ & $31: 12$ \\
Body mass index (median & $24 \cdot 2(18 \cdot 5-35)$ & $26 \cdot 6(16 \cdot 6-40 \cdot 8)$ \\
$\quad$ (range)) & $26: 8$ & $36: 7$ \\
$\begin{array}{l}\text { Smokers (no:yes) } \\
\text { Alcohol intake (g/day) } \\
\text { (median (range)) }\end{array}$ & $2 \cdot 5(0-30)$ & $3 \cdot 0(0-48)$ \\
\hline
\end{tabular} \\ Gastroenterology, Queen \\ 31 May 1992
}


ing to a recently proposed modification of the original Savary and Miller classification." Barrett's oesophagus was diagnosed if the columnar mucosa extended $3 \mathrm{~cm}$ or more into the oesophagus above the gastro-oesophageal junction. The severity of oesophagitis in patients with Barrett's oesophagus was classified in the same way as in other patients and depended on the endoscopic appearance of the oesophageal mucosa above the neosquamocolumnar junction. Patients were questioned in detail about their symptoms and each patient was accorded a symptom score. ${ }^{16}$

\section{CONTROLS}

Thirty four healthy volunteers ( 22 men) with a median age of 33.5 years (range 22-51) comprised the control group. They were totally asymptomatic and had no history of oesophageal, gastric, or duodenal disease.

\section{METHODS}

\section{Radionuclide oesophageal transit}

The details of this test have been described before. ${ }^{17}$ All studies were performed in the fasting state (no food or drink for $>$ six hours). The subject was asked to swallow a $10 \mathrm{ml}$ bolus of water labelled with $1 \mathrm{mCi}(37 \mathrm{MBq})$ of Tc-99m (sulphur colloid) followed by dry swallows every 15 seconds. A total of 180 one second frames were taken and stored on an online computer. The test was done in both erect and supine positions. Time versus activity curves were generated for the proximal, middle, and distal thirds of the oesophagus and the whole of the oesophagus. Transit times were measured as the interval between the initial appearance to the disappearance of more than $90 \%$ of the peak counts. If there was persistent delayed transit at the end of the three minute period, the transit time was regarded as 180 seconds.

\section{Manometry}

All drugs were stopped at least 48 hours beforehand. The test was done in the fasting state $(>$ six hours). A three lumen catheter of $3.6 \mathrm{~mm}$ external diameter and $0.9 \mathrm{~mm}$ internal diameter (each lumen) was used. The three sideholes were oriented radially at $120^{\circ}$ to one another and were $5 \mathrm{~cm}$ apart. The catheter was perfused continuously with water at the rate of $0.6 \mathrm{ml} /$ minute using a pneumohydraulic infusion pump (Arndorfer, USA). The output was recorded on a four channel Lectromed polygraph recorder. Lower oesophageal sphincter pressure was measured with the rapid pull through technique. This was done three times giving nine readings. The manometry catheter was then positioned $5 \mathrm{~cm}$ above the upper border of the lower oesophageal sphincter so that the distal, middle, and proximal ports were 5,10 , and $15 \mathrm{~cm}$ from the lower oesophageal sphincter respectively. Some $15-20,5 \mathrm{ml}$ water swallows were given 20-30 seconds apart. The last 10 consecutive swallows were used for analysis of the oesophageal body motility.

\section{Acid clearance test}

The acid clearance test was performed using the technique originally described by Booth et al with some modifications. The test was done immediately after manometry. The manometry catheter and an antimony $\mathrm{pH}$ electrode (Synectics Ltd) were positioned $5 \mathrm{~cm}$ above the lower oesophageal sphincter. A reference electrode was attached to the patient's forearm and both the electrodes were connected to a recording device (Digitrapper, Synectics).

A $15 \mathrm{ml}$ bolus of $0 \cdot 1 \mathrm{~N}$ hydrochloric acid $(\mathrm{HCl})$ was instilled into the oesophagus using the proximal port of the manometry catheter so that it arrived $15 \mathrm{~cm}$ above the lower oesophageal sphincter. The subject was then asked to swallow (dry) every 30 seconds. Acid clearance time was measured in seconds as the interval from the time of instillation of $\mathrm{HCl}$ to the time the $\mathrm{pH}$ rose to 5 and stayed at or above that level for 60 seconds. If the $\mathrm{pH}$ failed to come up to 5 after 20 minutes (1200 seconds), the acid clearance time was regarded to be 1200 seconds. The test was done in sitting and supine postures.

For this test, the subjects were divided into two groups. The first group consisted of the first 15 consecutive patients and 11 consecutive volunteers who were asked not to swallow any saliva (they were asked to spit it out). In the second group (the next 23 patients and 23 volunteers), the subjects were allowed to swallow saliva at 30 second intervals. The acid clearance test failed to discriminate between patients and volunteers in the first group as it was grossly prolonged in most of the subjects (both patients and volunteers). This was thought to be due to the lack of the acid neutralising effect of the saliva. An acid clearance test was not possible in five patients because of their inability to tolerate nasal passage of the $\mathrm{pH}$ probe while the manometry catheter was still in situ. The acid clearance data presented here are from the second group of subjects ( 23 patients and 23 volunteers).

\section{Hour oesophageal pH monitoring}

The method used for this test followed the recommendations of a recent working team report. ${ }^{18}$ An antimony $\mathrm{pH}$ probe (Synectics Ltd) was positioned $5 \mathrm{~cm}$ above the upper border of the lower oesophageal sphincter and a reference electrode was attached to the chest. Both electrodes were connected to a solid state recording device (Digitrapper, Synectics). Monitoring was continued for 24 hours. Subjects were asked to keep a record of the time of posture changes, food intake, and the occurrence of symptoms in a diary. No drugs were permitted at least 48 hours beforehand and during the monitoring. Patients who had repeat 24 hour $\mathrm{pH}$ monitoring at the second stage of the study were still taking omeprazole $40 \mathrm{mg} /$ day but all other drugs were withheld for at least 48 hours beforehand. The data were analysed using Esophogram software (Synectics). Data from one patient at the first stage and another one at the second stage and from two volunteers had to be excluded because of appreciable probe drift, apparent at probe calibration after the test.

All patients were treated with omeprazole 40 


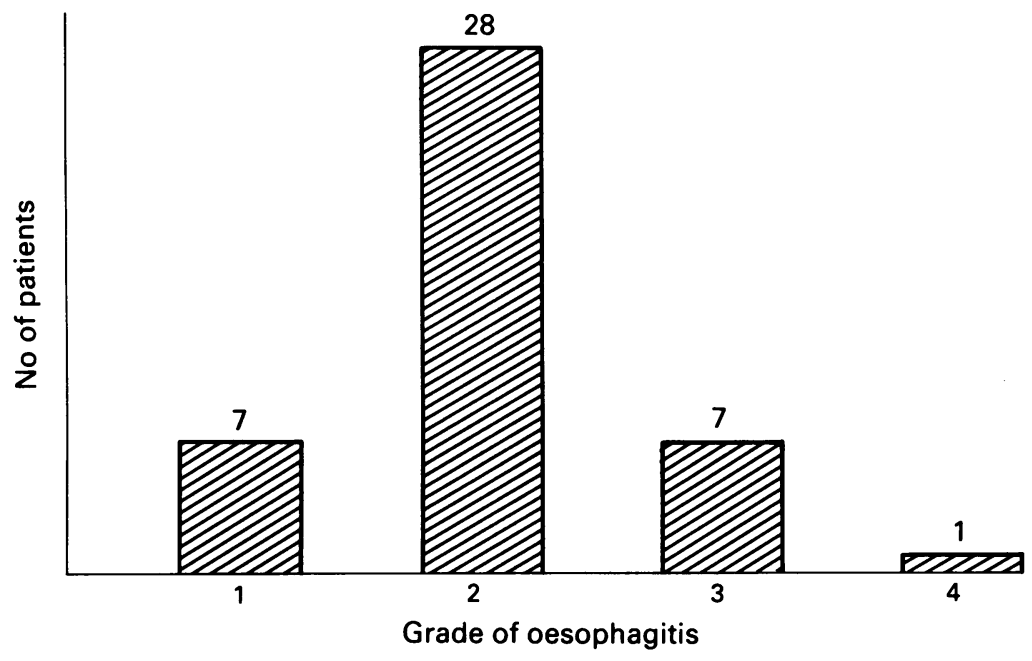

Figure 1: The distribution of grades of oesophagitis in 43 patients.

$\mathrm{mg} /$ day for a median duration of 12 weeks (range 8-23), at which time endoscopy showed complete healing of oesophagitis, defined as $100 \%$ reepithelialisation of the oesophageal mucosa. Oesophagitis was still present at the second endoscopy in three patients and the treatment had to be continued for a further four to six weeks, when a third endoscopy confirmed complete healing.

The tests mentioned above were repeated within a week after the endoscopy showed complete healing of oesophagitis. Patients were still taking omeprazole when they had the tests done for a second time. Controls had the tests on one occasion only.

All manometry tracings and radionuclide transit curves were coded and analysed together in a blinded fashion after the study was closed. Lower oesophageal sphincter pressure was measured as the mean from nine rapid pull through readings. Oesophageal body amplitudes were calculated at 5 (distal), 10 (middle), and 15 (proximal) $\mathrm{cm}$ above the lower oesophageal sphincter as the mean of 10 consecutive readings. The duration of contraction was also measured separately for each level in the same way. The velocity of propagation was measured in $\mathrm{cm} /$ second as the mean of 10 consecutive values by determining the time interval in seconds between the beginning of the upstroke of the contractions at 5 and $15 \mathrm{~cm}$ above the lower oesophageal sphincter and then dividing 10 (the distance in $\mathrm{cm}$ between the proximal and distal ports) by that figure. Peristalsis was considered 'failed' either if there was no contraction wave at all, or if it failed to traverse the entire length of the oesophagus, or if a simultaneous contraction occurred. Any episodes of failed peristalsis were excluded from further analysis of the peristaltic wave characteristics. One patient showed $100 \%$ aperistalsis both before and after treatment, and it was not therefore possible to measure amplitude, duration, or velocity of propagation in this patient.

\section{STATISTICAL ANALYSIS}

The Mann-Whitney U test was used to compare data between patients and controls. Paired data were analysed using Wilcoxon's signed rank test. The $\chi^{2}$ test with Yates's correction and Fisher's exact test were performed to compare the incidence of cumulative manometric abnormalities and failed peristalsis between patients and controls. The McNemar test was used to compare the incidence of failed peristalsis in patients before and after healing of oesophagitis. General linear model (GLM) of analysis of variance was used to examine the association between various oesophageal function parameters and patient characteristics such as age, sex, smoking, alcohol consumption, body mass index, degree of oesophagitis, and presence or absence of hiatus hernia and Barrett's oesophagus. A p value of $<0.05$ was regarded as statistically significant.

\section{Results}

The demographic characteristics of the patients and controls are given in Table I. The distribution of grades of oesophagitis is shown in Figure 1. Hiatus hernia was present in 33 patients. Nine patients had Barrett's oesophagus. Hiatus hernia was absent in only one of the nine patients with Barrett's oesophagus. A summary of the results of this study is presented in Table II.

\section{OESOPHAGEAL TRANSIT}

Patients had significantly longer median oesophageal transit times than controls in both

TABLE II Summary of the parameters of oesophageal function in control subjects and in patients before and after healing of oesophagitis

\begin{tabular}{|c|c|c|c|c|c|}
\hline \multirow{2}{*}{ 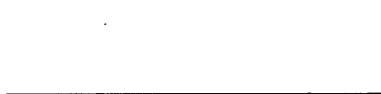 } & \multirow{2}{*}{$\begin{array}{l}\text { Controls } \\
(\text { median } \\
\text { (range) })\end{array}$} & \multicolumn{2}{|c|}{ Patients (median (range)) } & \multirow{2}{*}{$\begin{array}{l}\text { Patients (before) } \\
\text { v controls } \\
(p(95 \% C I))\end{array}$} & \multirow{2}{*}{$\begin{array}{l}\text { Patients before } \\
\text { v after } \\
(p(95 \% C I))\end{array}$} \\
\hline & & Before & After & & \\
\hline \multicolumn{6}{|l|}{ Transit time (seconds): } \\
\hline Erect & $7(4-24)$ & $9(4-180)$ & $9(3-100)$ & $0.027(0.001,3.0)$ & $0.4(-0.32,3 \cdot 0)$ \\
\hline Supine & $11(7-180)$ & $17(5-180)$ & $24(6-180)$ & $0.002(1 \cdot 0,15 \cdot 0)$ & $0.78(-2 \cdot 0,2 \cdot 0)$ \\
\hline LOS pressure $(\mathrm{mm} \mathrm{Hg})$ & $22 \cdot 5(8-40)$ & $16 \cdot 5(6 \cdot 5-44)$ & $20(5-49 \cdot 5)$ & $0.017(-9 \cdot 5,-1 \cdot 0)$ & $0 \cdot 142(-4 \cdot 2,0 \cdot 2)$ \\
\hline \multicolumn{6}{|l|}{ Amplitude $(\mathrm{mm} \mathrm{Hg})$ : } \\
\hline $\begin{array}{l}\text { Distal } \\
\text { Middle }\end{array}$ & $\begin{array}{l}92(44-168) \\
79(33-176)\end{array}$ & $\begin{array}{l}32(11-132) \\
46(14-135)\end{array}$ & $\begin{array}{l}60(12 \cdot 3-16 /) \\
49(19-141)\end{array}$ & $0.0001(-46.5,-14.5)$ & $0 \cdot 114(-9 \cdot 0,2 \cdot 2)$ \\
\hline Proximal & $42(20-81 \cdot 5)$ & $36(8-105 \cdot 5)$ & $36(10 \cdot 5-120)$ & $0 \cdot 10(-16 \cdot 5,2 \cdot 0)$ & $0 \cdot 435(-4 \cdot 3,2 \cdot 0)$ \\
\hline \multicolumn{6}{|l|}{ Duration of contraction (seconds): } \\
\hline Distal & $2 \cdot 7(1 \cdot 9-5 \cdot 0)$ & $3 \cdot 1(2 \cdot 0-10 \cdot 2)$ & $3 \cdot 1(1 \cdot 6-6 \cdot 6)$ & $0 \cdot 017(0 \cdot 1,0 \cdot 9)$ & $0.326(-0.28,0.65)$ \\
\hline Middle & $2 \cdot 5(1 \cdot 8-5 \cdot 1)$ & $3 \cdot 0(2 \cdot 0-9 \cdot 0)$ & $3 \cdot 0(1 \cdot 7-5 \cdot 5)$ & $0.005(0.1,0.8)$ & $0.333(-0.28,0.48)$ \\
\hline Proximal & $2 \cdot 2(1 \cdot 2-4 \cdot 2)$ & $2 \cdot 8(1 \cdot 3-7 \cdot 2)$ & $2 \cdot 5(1 \cdot 4-5 \cdot 2)$ & $0.001(0 \cdot 3,1 \cdot 1)$ & $0.093(-0.1,0.78)$ \\
\hline Velocity of propagation ( $\mathrm{cm} / \mathrm{second}$ ) & $4 \cdot 1(2 \cdot 6-6 \cdot 4)$ & $3 \cdot 3(1 \cdot 9-6 \cdot 3)$ & $3 \cdot 3(1 \cdot 6-5 \cdot 5)$ & $0 \cdot 006(-1 \cdot 1,-0 \cdot 2)$ & $0 \cdot 582(-0 \cdot 2,0 \cdot 1)$ \\
\hline \multicolumn{6}{|c|}{ Acid clearance time (seconds): } \\
\hline Sitting & $288(90-780)$ & $350(110-975)$ & $371(55-860)$ & $0.044(4,225)$ & $0.322(-76,120)$ \\
\hline Supine & $405(133-1200)$ & $536(180-1200)$ & $645(235-1200)$ & $0.016(35,358)$ & $0 \cdot 322(-189,63)$ \\
\hline
\end{tabular}

LOS $=$ lower oesophageal sphincter; $95 \% \mathrm{CI}=95 \%$ confidence interval. 


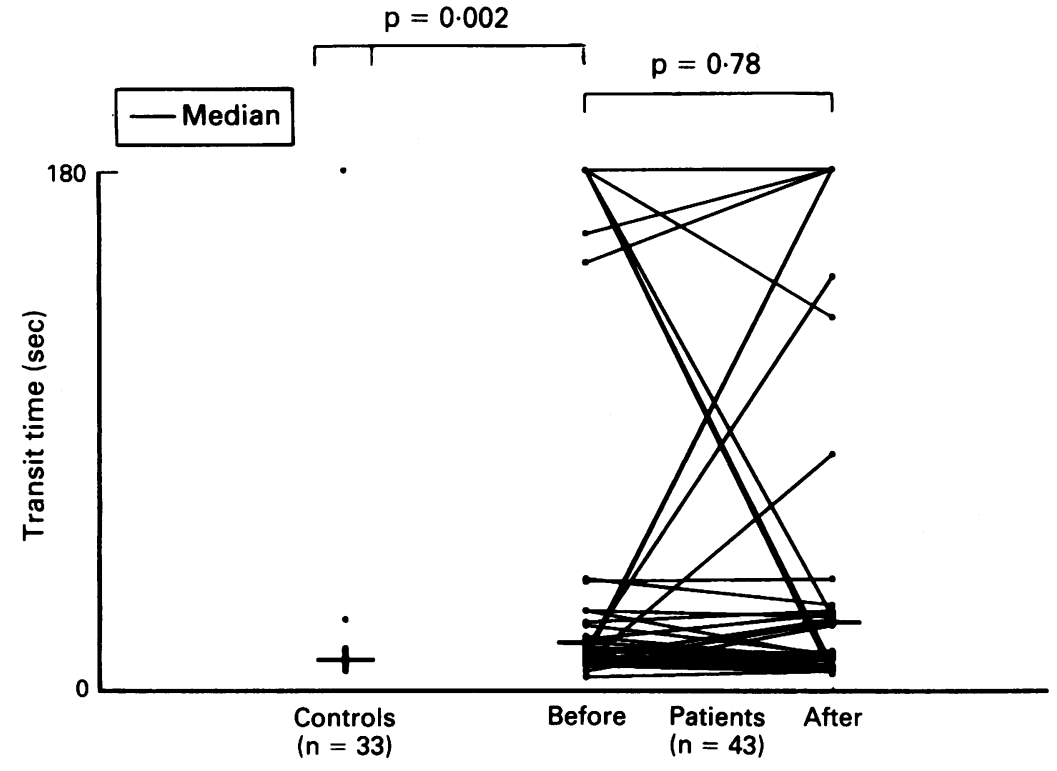

Figure 2: Radionuclide oesophageal transit in supine posture in 33 controls and 43 patients before and after healing of oesophagitis.

erect and supine postures $(9 v 7$ and $17 v 11$ seconds with the corresponding $\mathrm{p}=0.027$ and 0.002 for erect and supine postures respectively). This was because of delayed transit in the distal oesophagus in patients compared with controls $(8 v 7$ and $17 v 11$ seconds with the corresponding $p=0.02$ and 0.002 for erect and supine postures respectively). There was no significant change in the median transit time after healing of oesophagitis $(9 v 9$ and $17 v 24$ seconds for erect and supine postures respectively). Figure 2 shows the results of the oesophageal transit study in supine posture.

\section{MANOMETRY}

Patients had significantly lower median lower oesophageal sphincter pressures than controls (16.5 $v 22.5 \mathrm{~mm} \mathrm{Hg} ; \mathrm{p}=0.017)$. There was no significant change in the median lower oesophageal sphincter pressure after healing of oesophagitis (16.5 v $20 \mathrm{~mm} \mathrm{Hg}$ after healing (Fig 3)). The median distal and middle oesophageal amplitudes were considerably lower in patients than in oesophageal sphincter (LOS) pressure in 34 controls and 43 patients before and after healing of oesophagitis.

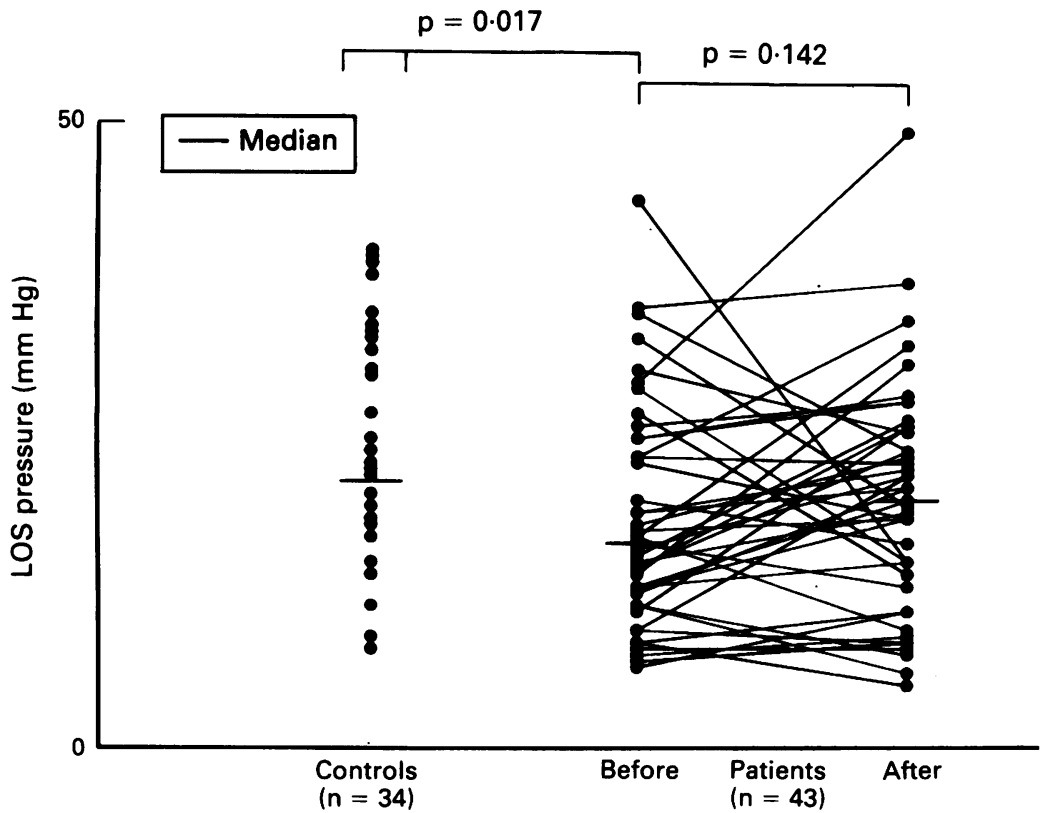

controls (52 v 92; $46 v 79 \mathrm{~mm} \mathrm{Hg}$ for distal and middle oesophagus respectively; $\mathrm{p}=0.0001$ ) The patients also tended to have lower median proximal oesophageal amplitudes than controls but this failed to reach statistical significance (36 v $42 \mathrm{~mm} \mathrm{Hg} ; \mathrm{p}=0 \cdot 1)$. There was no significant change in oesophageal amplitudes after the healing of oesophagitis $(52 v 60 ; 46 v 49 ; 36 v 36 \mathrm{~mm}$ $\mathrm{Hg}$ for distal, middle, and proximal oesophagus respectively). The distal oesophageal amplitudes in controls and patients are shown in Figure 4. The median durations of contraction in all three segments of oesophagus were significantly longer in patients than in controls $(3.1 v 2.7 ; 3.0 v 2.5$; $2.8 v 2.2$ seconds with the corresponding $\mathrm{p}=$ 0.017 ; 0.005 ; and 0.001 for distal, middle, and proximal oesophagus respectively). There was no significant change in the durations of contraction after the healing of oesophagitis $(3.1 v 3 \cdot 1$; $3.0 v 3.0 ; 2.8 v 2.5$ seconds for the distal, middle, and proximal oesophagus respectively). The median velocity of propagation of contraction was considerably lower in patients than in controls $(3.3 v 4 \cdot 1 \mathrm{~cm} / \mathrm{second} ; \mathrm{p}=0 \cdot 006)$. There was no significant change in the propagation velocity after healing of oesophagitis $(3.3 v 3.3 \mathrm{~cm} /$ second (Fig 5)). Failed peristalsis was commonly encountered in patients as well as controls. Using the 95th centile of the percentage of failed peristalsis in controls $(26.9 \%)$, seven patients before treatment and seven patients after healing of oesophagitis were classified as having an abnormally high incidence of failed peristalsis. Fisher's exact test, however, failed to show any statistically significant difference between the patients and controls.

Cumulative analysis of manometric abnormalities For this purpose, the 5th centile values of the distal ( $<44 \mathrm{~mm} \mathrm{Hg}$ ) and mid-oesophageal $(<36$ $\mathrm{mm} \mathrm{Hg}$ ) peristaltic amplitudes and the lower oesophageal sphincter pressure $(<9 \mathrm{~mm} \mathrm{Hg})$ and the 95th centile of the percentage of failed peristalsis $(>26.9 \%)$ were taken as the cut off points for abnormality. Subjects who had abnormal results for one or more of these parameters were regarded as having abnormal manometry. Using these criteria, three of the 34 controls were classified as abnormal, while 22 of the 43 patients in both the pretreatment group and the post-healing group were similarly classified. Seventeen patients were classified as abnormal both before and after healing. Five patients classified as abnormal before healing were classified normal after healing. Conversely, five patients who were classified normal before healing were classified as abnormal after healing. There was a highly significant difference between controls and patients both before and after healing ( $\chi^{2}$ with Yates's correction $=13.65$; $\mathrm{p}<0.005)$. There was no significant change in patients after healing of oesophagitis $\left(\chi^{2}=0 \cdot 000\right)$.

\section{ACID CLEARANCE TEST}

Median acid clearance times in both sitting and supine postures were significantly longer in patients than controls $(350 v 288$ and $536 v 405$ seconds and the corresponding $\mathrm{p}=0.044$ and 


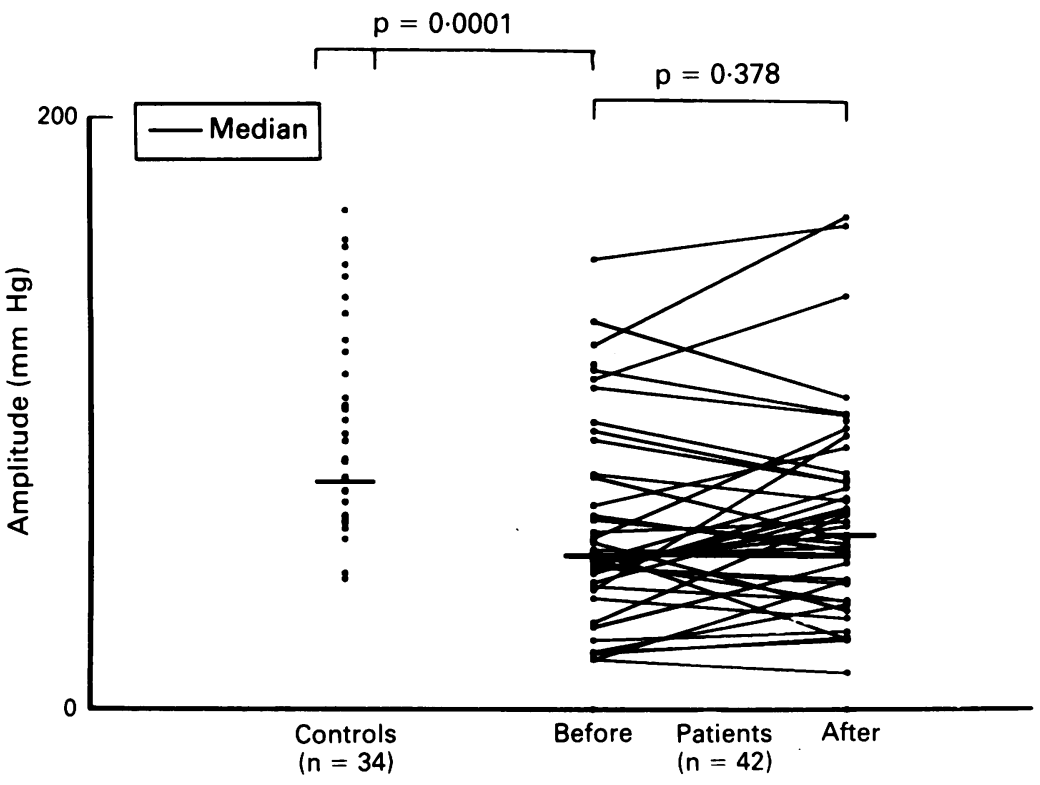

Figure 4: Peristaltic amplitude in distal oesophagus ( $5 \mathrm{~cm}$ above lower oesophageal sphincter) in 34 controls and 42 patients before and after healing of oesophagitis. One patient had $100 \%$ aperistalsis both before and after healing and was therefore excluded from analysis of the oesophageal body peristaltic amplitude, duration, and velocity.
Figure 5: Velocity of propagation in 34 controls and 42 patients before and after healing of oesophagitis. One patient was excluded because of $100 \%$ aperistalsis both before and after

healing.

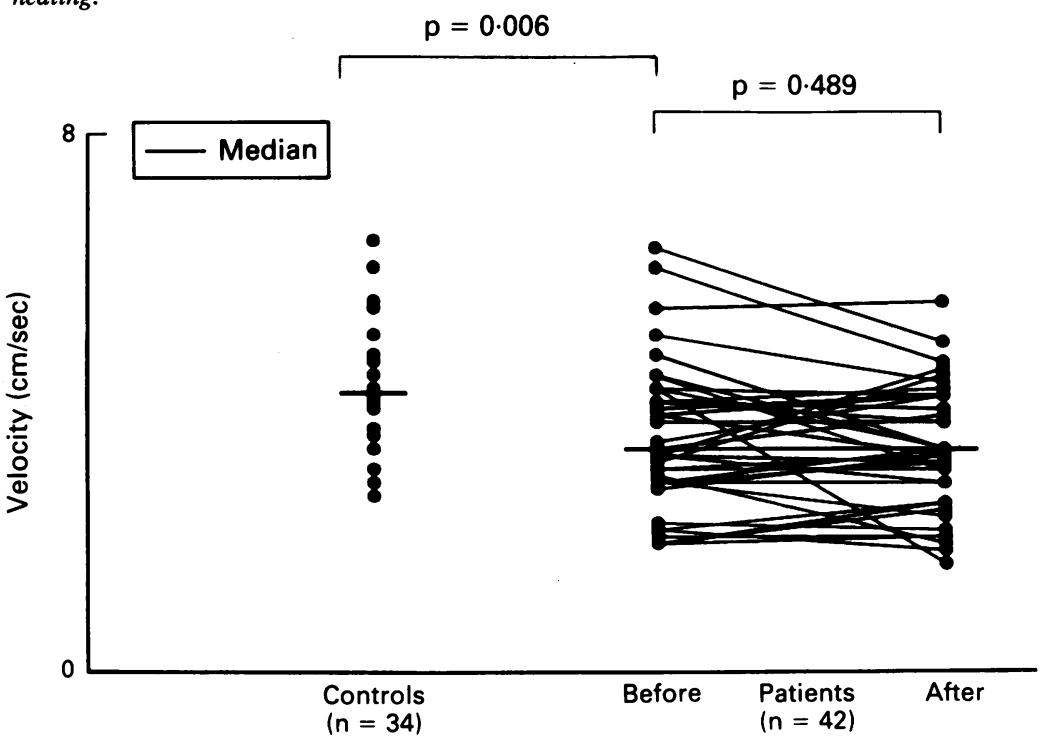
median \% of total time the $\mathrm{pH}<4(10.7 v 0.8$; $\mathrm{p}<0.001$ ). Using our criteria of abnormality (\% total time pH below $4>4.9 \%$ ), the results were abnormal in six of the 31 patients at the second stage of the study.
Univariate analysis was undertaken initially to examine the effect of a number of individual patient characteristics (age, sex, body mass index, smoking, alcohol consumption, hiatus hernia, grade of oesophagitis, and presence or absence of Barrett's oesophagus) on the indices of oesophageal function (oesophageal transit times, lower oesophageal sphincter pressure, oesophageal body amplitudes, durations of contraction, velocity of propagation, and acid clearance times). Any patient characteristics which gave a $\mathrm{p}$ value of $\leq 0 \cdot 1$ or less were then used together in a multifactorial model in an analysis of variance with each index of oesophageal function being the dependent variable. The presence of Barrett's oesophagus was found to have a significant positive association with transit time in supine position $(p=0.003)$ and a negative association with lower oesophageal sphincter pressure $(p=0 \cdot 05)$. None of the other variables had any significant effect. These results were confirmed when patients with Barrett's oesophagus were compared separately as a group with patients without Barrett's oesophagus using the Mann-Whitney U test. Patients with Barrett's oesophagus tended to have significantly longer median oesophageal transit times in supine posture $(180 v 13.5$ seconds; $\mathrm{p}=0.0004)$ but there was no difference in the erect posture. Patients with Barrett's oesophagus also had significantly lower median lower oesophageal sphincter pressures $(9.5 v 17 \mathrm{~mm} \mathrm{Hg} ; \mathrm{p}=0.014)$ but there was no difference in any of the other manometric parameters. The number of patients with Barrett's oesophagus who had an acid clearance test was too small (three) to make any valid comparisons with the patients without Barrett's oesophagus. periods was considerably higher in patients than in controls $(9.2 v 1.6 ; 5.4 v 0.3 ; 10.3 v 2.2$ respectively; $\mathrm{p}<0.0001$ ).

Paired 24 hour pH monitoring data (before and after healing) were available in 31 patients. There was a very significant reduction in the

\section{HOUR OESOPHAGEAL PH MONITORING}

hour oesophageal $\mathrm{pH}$ monitoring showed significant acid reflux (defined as \% of total time $\mathrm{pH}$ less than $4>4.9 \%$ ). The median $\%$ of time the $\mathrm{pH}$

Discussion

Several studies have documented the association between reflux oesophagitis and oesophageal motor abnormalities. It has been known that patients with reflux oesophagitis, as a group, tend to have reduced lower oesophageal sphincter pressures, increased incidence of failed peristalsis, and reduced peristaltic amplitudes. ${ }^{2}$ The velocity of propagation has been shown to be slower in patients with reflux oesophagitis. ' ${ }^{\times}$Gill et $a l^{8}$ have reported shorter durations of contraction in this condition. Oesophageal transit and acid clearance have also been shown to be slower in these patients. ${ }^{46}$ Our study is broadly in agreement with those previously reported observations, with the exception that our patients had longer durations of contraction compared with the controls in contrast to the findings of Gill et al. ${ }^{\star}$ At present we are unable to offer any explanation for this disparity.

There have been a number of studies attempting to look at the vexed question of the effect of healing of oesophagitis on oesophageal function. Most of these have serious methodological problems. Gill et $a l^{\star}$ studied the effects of fundoplication on basal lower oesophageal sphincter pressures and oesophageal body motility in patients with symptoms of gastro-oesophageal reflux disease. They showed improvements in lower oesophageal sphincter pressures and 


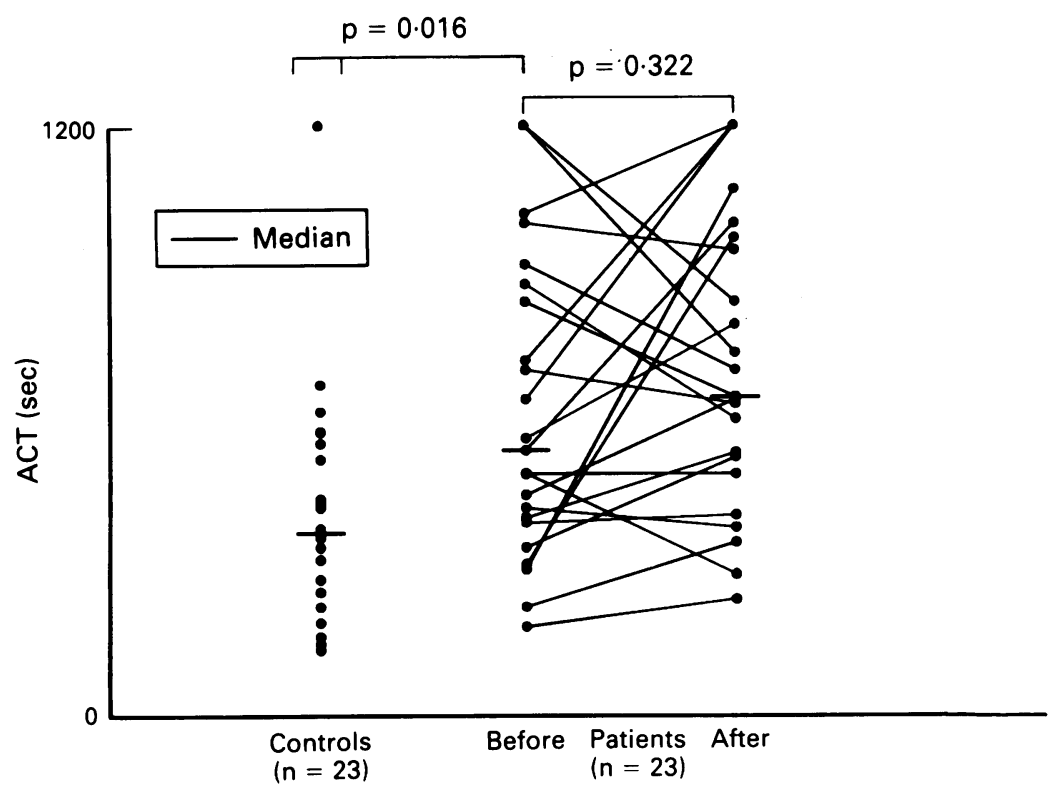

Figure 6: Acid clearance times $(A C T)$ in supine posture in 23 controls and 23 patients before and after healing of oesophagitis.

peristaltic amplitudes. Nearly half the patients entered in their study, however, did not have endoscopic or any other firm evidence to support the diagnosis of gastro-oesophageal reflux disease and the patient population could possibly have included subjects who had some other disease (gall stones, non-ulcer dyspepsia, etc). Secondly, the improvement in lower oesophageal sphincter pressure could simply have been an artifact produced by the surgical procedure. ${ }^{4}$ Thirdly, the improvement in peristaltic amplitudes was associated with a significant increase in the duration of contraction raising the possibility that it simply reflected a response to a degree of obstruction at the level of the lower oesophageal sphincter. This impression is further supported by their observation that the lower oesophageal sphincter relaxation was incomplete in most patients after surgery. In another study," prolonged oesophageal transit in a group of patients with gastro-oesophageal reflux disease persisted after a surgical antireflux procedure. In this study, there was no objective assessment made by endoscopy or any other procedure to record the effect of surgery in terms of healing or otherwise of the oesophagitis. Interpretation of the studies involving surgery is made very difficult by the problem of anatomical and functional changes caused by the surgical procedure itself. Fundoplication may place a degree of stretch on the smooth muscle of the body of the oesophagus and could thus increase the amplitude of contractions. ${ }^{\times}$

Studies on the effects of medical healing of oesophagitis suffer from the drawbacks of small numbers ${ }^{23} 7_{12-14}$ and the fact that some of them have included in their analysis patients who showed improvement in rather than complete healing of oesophagitis. ${ }^{7113}$

Our study is different in that the numbers are larger, the entry criteria and the endpoints are strictly defined, and many more indices of oesophageal function have been examined. The availability of omeprazole allowed us to achieve complete healing of oesophagitis in all our patients which would not have been possible before this drug was available.

The patients in this study were older than the controls but that is unlikely to have had a significant effect on our results. Using analysis of variance in unifactorial and multifactorial models, age did not seem to have a bearing on any of the parameters of oesophageal function. This was true for patients as well as the control group. Richter et $a l,{ }^{19}$ in their large study of oesophageal manometry in 95 volunteers, showed that age had no effect on lower oesophageal sphincter pressure but older volunteers had higher amplitudes and longer durations of contraction in the distal oesophagus than the younger ones. In their study, age had no effect on the velocity of propagation and amplitudes or durations of contraction higher up the oesophagus.

It should be noted that at the second stage of the study (after the healing of oesophagitis) the patients were still taking omeprazole. It could, therefore, be argued that omeprazole may have influenced our results either through a possible direct effect on the various parameters of oesophageal function or indirectly through other mechanisms such as hypergastrinaemia. However, this is unlikely to have affected our results. Gastrin is thought to actually increase the lower oesophageal sphincter pressure ${ }^{211}$ and therefore any effects caused by this factor would not have materially changed the results of our study. Also, a number of recent studies on the effect of omeprazole on lower oesophageal sphincter pressure and oesophageal body motility have shown no effect. $131+21$

We have shown clearly that as a group patients with reflux oesophagitis have a number of oesophageal motor abnormalities. It was noticeable in our study that oesophageal peristaltic dysfunction was a commoner and more pronounced abnormality than reduced lower oesophageal sphincter pressure, which suggests that impaired oesophageal clearance may play a larger part in the pathophysiology of this condition than the defective barrier function of the lower oesophageal sphincter. We have shown that the abnormalities of oesophageal motor function in patients with reflux oesophagitis do not improve after complete healing of oesophagitis. This suggests that oesophageal dysmotility in this condition is a primary phenomenon and not a consequence of injury and inflammation. This is consistent with two recent studies describing a high prevalence of impairment of vagal cardiovascular reflexes in patients with gastro-oesophageal reflux disease. ${ }^{2223}$

These results have important implications for the understanding of the natural history of gastro-oesophageal reflux disease. At present we can only speculate about the nature of the origin of the oesophageal motor abnormalities and their role in the 'eventual' development of reflux disease and oesophagitis. It is possible that those who are 'destined' to develop reflux oesophagitis have predisposing oesophageal motor abnormalities that may well have an inherited component. Studies involving families of the patients may provide some of the answers.

We are indebted to the Reckitt and Coleman Pharmaceuticals and the Wessex Regional Health Authority for funding this project. We are grateful to Bernard Higgins for his help with the statistical analysis. 
Some of these data were presented at the Spring 1990, and the Autumn and Spring 1991 meetings of the British Society of Gastroenterology and published in Gut in abstract form.

1 Kahrilas PJ, Dodds WJ, Hogan WJ, Kern M, Arndorfer RC, Reece A. Esophageal peristaltic dysfunction in peptic esophagitis. Gastroenterology 1986; 91: 897-904.

2 Katz PO, Knuff TE, Benjamin SB, Castell DO. Abnorma esophageal pressures in reflux esophagitis: cause or effect? Am $\mathcal{F}$ Gastroenterol 1986; 81: 744-6.

3 Eckardt VF. Does healing of esophagitis improve esophageal motor function? Dig Dis Sci 1988; 33: 161-5.

4 Eriksen CA, Sadek SA, Cranford C, Sutton D, Kennedy N, Cuschieri A. Reflux oesophagitis and oesophageal transit: evidence for a primary oesophageal motor disorder. Gut 1988; 29: 448-52.

5 Booth DJ, Kemmerer WT, Skinner DB. Acid clearing from the distal oesophagus. Arch Surg 1968; 96: 731-4.

6 Little AG, DeMeester TR, Kirchner PT, O'Sullivan GC Skinner DB. Pathogenesis of esophagitis in patients with gastroesophageal reflux. Surgery $1980 ; 88: 101-7$.

7 Baldi F, Ferrarini F, Longanesi A, Angeloni M, Ragazzini $M$ Miglioli M, et al. Oesophageal function before, during and after healing of erosive oesophatis. Gut 1988;29:157-60.

8 Gill RC, Bowes KL, Murphy PD, Kingma YJ. Esophagea motor abnormalities in gastroesophageal reflux and the motor abnormalities in gastroesophageal reflux and the

9 Bancewic\% J, Mughal M, Marples M. The lower oesophagea sphincter after floppy Nissen fundoplication. Br $\mathcal{F}$ Surg 1987; 74: $162-4$

10 Russell COH, Pope CE, Gannan RM, Allen FD, Velasco N, Hill LD. Does surgery correct esophageal motor dysfunction in gastroesophageal reflux? Ann Surg 1981; 194: 290-6.

11 Sonnenberg A, Lepsien G, Muller-Lissner SA, Koelz HR Siewart JR, Blum AL. When is esophagitis healed? Esophageal endoscopy, histology and function before and after cimetidine treatment. Dig Dis Sci 1982; 27: 297-302.

12 Holloway RH, Tippett $M$, Dent J. Effect of healing of oesophagitis on oesophageal motor function in patients with ulcerative peptic oesophagitis. Aust NZ F Med 1989; 19 (suppl 1): 592

13 Howard JM, Frei JV, Flowers M, Bondy DC, Tilbe $\mathrm{K}$ Reynolds RPE. Omeprazole heals esophagitis but does not improve abnormal esophageal motility in reflux esophagitis. Gastroenterology 1990; 98: A61.

14 Allen ML, Robinson MG, Richter JE, Stark GA, McIntosh DL, Dalton CB. The esophageal manometric effects of omeprazole therapy ( $20 \mathrm{mg}$ and $40 \mathrm{mg} \mathrm{AM}$ ). Gastroenterology 1989; 96: A8.

15 Colin-Jones DG Histamine-2-receptor antagonists in gastrooesophageal reflux. Gut 1989; 30: 1305-8.

16 Jamieson GG, Duranceau AC. The investigation and classification of reflux disease. In Jamieson GG, ed. Surgery of the tion of reflux disease. In Jamieson GG, ed. Surgery of the
oesophagus. Edinburgh: Churchill Livingstone, 1988: oesophagus.

17 Netscher D, Larson GM, Polk HC. Radionuclide esophageal transit. Arch Surg 1986; 121: 843-8.

18 Tytgat GNJ, Bennett JR, Dent J, Joelsson B. Oesophageal pH monitoring - normal and abnormal. Gastroenterology International 1989; 2: 141-9.

19 Richter JE, Wu WC, Johns DN, Blackwell JN, Nelson JL Castell JA, et al. Esophageal manometry in 95 healthy volunteers. Dig Dis Sci 1987; 32: 583-92.

20 Higgs RH, Smyth RD, Castell DO. Effect on lower esophagea sphincter pressure and serum gastrin. $N$ Eng $\mathcal{F} \mathrm{Med} 1974$ 291: 486-90.

21 Chakraborty TK, Caestecker JS, Pryde A, Heading RC. Effect of omeprazole on lower oesureal function in norma of omeprazole on lower oesophageal function in

22 Chakraborty TK, Ogilvie AL, Heading RC, Ewing DJ Abnormal cardiovascular reflexes in patients with gastrooesophageal reflux. Gut 1989; 30: 46-9.

23 Cunningham KM, Horowitz M, Riddell PS, Maddern GJ Myers JC, Holloway RH, et al. Relations among autonomic nerve dysfunction, oesophageal motility, and gastric empty ing in gastro-oesophageal reflux disease. Gut 1991; 32 